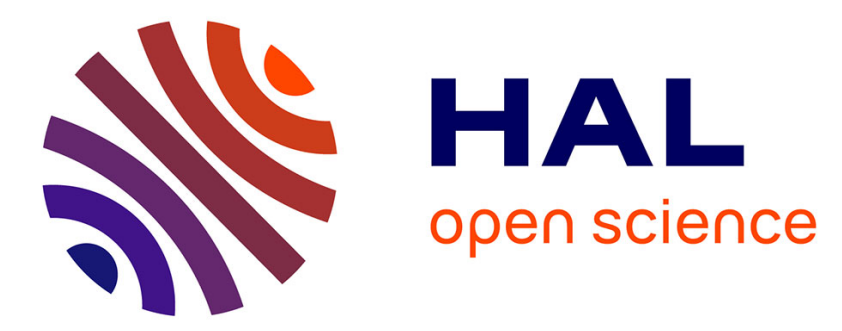

\title{
Redesigning solvatochromic probe Laurdan for imaging lipid order selectively in cell plasma membranes
}

Dmytro I Danylchuk, Erdinc Sezgin, Philippe Chabert, Andrey S Klymchenko

\section{To cite this version:}

Dmytro I Danylchuk, Erdinc Sezgin, Philippe Chabert, Andrey S Klymchenko. Redesigning solvatochromic probe Laurdan for imaging lipid order selectively in cell plasma membranes. Analytical Chemistry, 2020, 92 (21), pp.14798-14805. 10.1021/acs.analchem.0c03559 . hal-03086672

\section{HAL Id: hal-03086672 https://hal.science/hal-03086672}

Submitted on 22 Dec 2020

HAL is a multi-disciplinary open access archive for the deposit and dissemination of scientific research documents, whether they are published or not. The documents may come from teaching and research institutions in France or abroad, or from public or private research centers.
L'archive ouverte pluridisciplinaire $\mathbf{H A L}$, est destinée au dépôt et à la diffusion de documents scientifiques de niveau recherche, publiés ou non, émanant des établissements d'enseignement et de recherche français ou étrangers, des laboratoires publics ou privés. 


\title{
Redesigning solvatochromic probe Laurdan for imaging lipid order selectively in cell plasma membranes
}

\author{
Dmytro I. Danylchuk, ${ }^{1 \ddagger}$ Erdinc Sezgin, ${ }^{2,3}{ }^{3}$ Philippe Chabert ${ }^{1}$ and Andrey S. Klymchenko ${ }^{1 *}$ \\ ${ }^{1}$ Laboratoire de Bioimagerie et Pathologies, UMR 7021 CNRS, Université de Strasbourg, 74 route du Rhin, 67401, Illkirch, \\ France \\ ${ }^{2}$ MRC Human Immunology Unit, Weatherall Institute of Molecular Medicine, University of Oxford, Headley Way, Oxford \\ OX3 9DS, UK \\ ${ }^{3}$ Science for Life Laboratory, Department of Women's and Children's Health, Karolinska Institutet, 17177, Stockholm, \\ Sweden \\ *E-mail: andrey.klymchenko@unistra.fr
}

\begin{abstract}
Imaging of biological membranes by environment-sensitive solvatochromic probes, such as Laurdan, provides information about organization of lipids, their ordering and uneven distribution. To address a key drawback of Laurdan linked to its rapid internalization and subsequent labelling of internal membranes, we redesigned it by introducing a membrane anchor group based on negatively charged sulfonate and dodecyl chain. The obtained probe, Pro12A, stains exclusively the outer leaflet of lipid bilayers of liposomes, as evidenced by leaflet-specific fluorescence quenching with a viologen derivative, and shows higher fluorescence brightness than Laurdan. Pro12A also exhibits stronger spectral change between liquid ordered and liquid disordered phases in model membranes and distinguishes better lipid domains in giant plasma membrane vesicles (GPMVs) than Laurdan. In live cells it stains exclusively the cell plasma membranes, in contrast to Laurdan and its carboxylate analogue C-Laurdan. Owing to its outer leaflet binding, Pro12A is much more sensitive to cholesterol extraction than Laurdan that redistributes within both plasma membrane leaflets and intracellular membranes. Finally, its operating range in the blue spectral region ensures absence of cross-talk with a number of orange/red fluorescent proteins and dyes. Thus, Pro12A will enable accurate multicolor imaging of lipid organization of cell plasma membranes in the presence of fluorescently-tagged proteins of interest, which will open new opportunities in biomembrane research.
\end{abstract}

Imaging biological membranes and understanding their lipid ordering using molecular tools, such as fluorescent probes, has attracted significant interest in recent years. ${ }^{1-5}$ In particular, fluorescent environment-sensitive probes shed light on different fundamental properties of the biomembranes studied, including microviscosity, tension, polarity, and lipid order. ${ }^{6}$

Microscopic viscosity, essential for determination of lateral diffusion in biomembranes or in 3-dimentional cellular environment, also affects metabolism, enzymology and protein folding. ${ }^{7}$ This parameter can be measured exploiting excitedstate planarization in dyes termed molecular rotors. ${ }^{7-9}$ Imaging membrane tension opens the new opportunities in mechanobiology, with the help of ground-state planarizable probes, so-called flippers. ${ }^{10,11}$

Local membrane polarity, which is a complex parameter combining hydration, presence of dipoles, solvent relaxation and lipid order, ${ }^{2,12}$ can reflect various processes in cells, including apoptosis, ${ }^{13-15}$ starvation, ${ }^{16}$ oxidative stress $^{16-18}$ and can distinguish between normal and cancer cells. ${ }^{19}$ This parameter is studied by solvatochromic fluorescent dyes. ${ }^{6}$

Lipid order is of high importance for cell signaling, trafficking and membrane bioactivity. ${ }^{1,20}$ Plasma membrane reveals heterogeneity in lipid distribution at both lateral and transversal level. It is proposed that the interactions between sphingolipids and cholesterol (Chol) lead to the formation of nanoscale domains of higher lipid order. ${ }^{21,22}$ These domains are modelled in bilayers of saturated lipids and Chol, forming so-called liquid ordered (Lo) phase, which is clearly separated from the loosely packed liquid disordered phase (Ld) phase formed by unsaturated lipids. ${ }^{23-25}$ It is also known that in healthy cells, the outer leaflet contains mainly sphingomyelin (SM) and phosphatidyl choline, while the inner one is represented by phosphatidyl ethanolamine and phosphatidyl serine, ${ }^{26,27}$ which results in higher lipid order at the outer leaflet. ${ }^{28}$ Lipid order can be sensed either through monitoring the local viscosity by molecular rotors ${ }^{29}$ or lipid packing by mechanosensitive dyes ${ }^{11}$ as well as through local polarity using solvatochromic dyes ${ }^{6,30,31}$. Solvatochromic dyes generally detect ordered lipid phases as less polar environments, because their tight backing excludes polar water molecules and freezes dipolar relaxation processes. . $23,32,33$

The examples of solvatochromic dyes, used to sense lipid order, include Prodan ${ }^{34}$ and its lipophilic analogues Laurdan ${ }^{23,35}$ and C-Laurdan (Figure 1A), ${ }^{36}$ di-4-ANEPPDHQ, ${ }^{35,37}$ Nile 
$\operatorname{Red}^{33,38}$ and its derivatives (e.g. NR12S, NR12A and NR4A), ${ }^{33,39}$ push-pull pyrenes, ${ }^{40,41}$ dioxaborine (DXB-NIR), ${ }^{16}$ etc. Among these dyes, Prodan and Laurdan operate in the blue region of visible spectrum (emission maximum in lipid membranes $<500$ $\mathrm{nm}) .{ }^{23,35}$ Although this range is generally less attractive for bioimaging, it does not overlap with that of the majority of commonly used fluorescent proteins, which makes them compatible with multi-labeling protocols.

However, the application of Laurdan to live cells is limited due to its fast flip-flop to the inner leaflet and subsequent rapid internalization that leads to staining of intracellular membranes. ${ }^{35,42}$ An attempt to prevent internalization of Laurdan by introducing a carboxylate group (C-Laurdan) ${ }^{36}$ gave only a moderate improvement, because carboxylate may lose its negative charge by reprotonation. This issue can be effectively solved by changing the molecular design of the probe, namely by introducing membrane anchor groups, bearing an alkyl chain together with a zwitterionic group. ${ }^{33,43}$ Our recent study using solvatochromic Nile Red showed that a further improvement in the plasma membrane targeting can be achieved by replacing the zwitterionic head group with an anionic sulfonate. ${ }^{39} \mathrm{We}$ hypothesized that the use of this anionic anchor for Prodan fluorophore could result in an analogue that can specifically target cell plasma membrane with minimal internalization, while being sensitive to lipid order and compatible with common fluorescent proteins and dyes used in bioimaging.

The aim of current work is to create a cell-impermeable Prodan/Laurdan-based fluorescent probe that targets the outer biomembrane leaflet for live-cell imaging of plasma membranes and deciphers their lipid order.

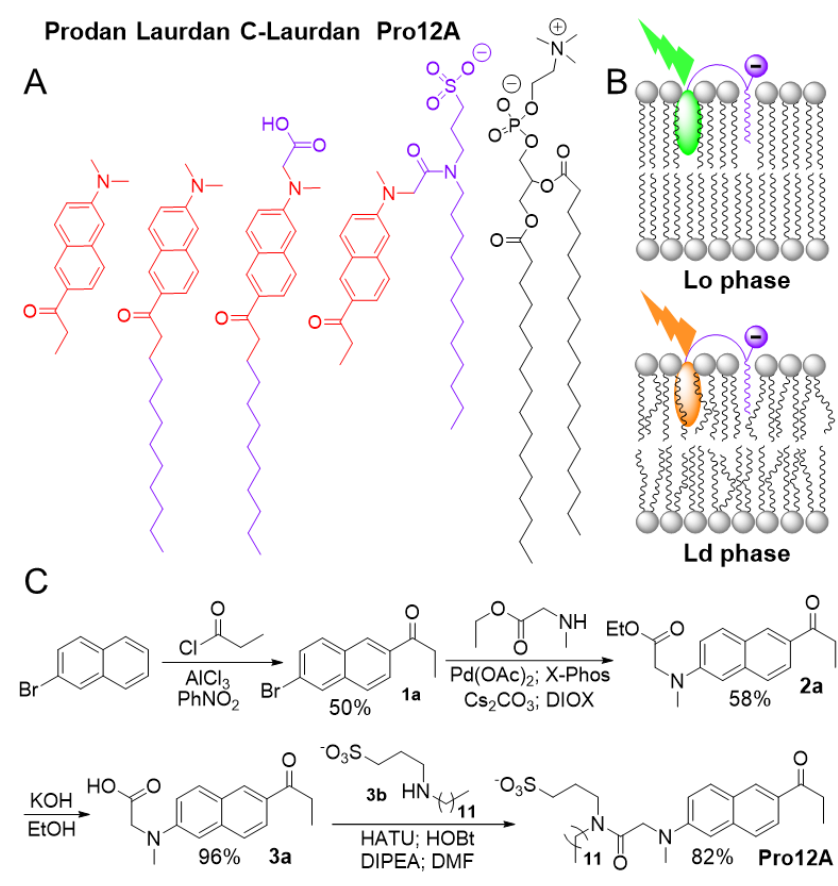

Fig 1. Chemical design (A), sensing principle (B) and synthesis (C) of Pro12A probe for lipid membranes. (A) Part in red highlights Prodan fluorophore in different membrane probes. (B) Schematic presentation of lipid bilayers presenting Lo and Ld phases and the color response of the solvatochromic probe to the changes in the lipid order.

\section{EXPERIMENTAL SECTION}

Materials and characterization of compounds. All the reagents were purchased from Sigma-Aldrich or Alfa Aesar or TCI and used as received. MilliQ-water (Millipore) was used in all experiments. NMR spectra were recorded at $20^{\circ} \mathrm{C}$ on a BrukerAvance III $400 \mathrm{MHz}$ spectrometer. Mass spectra were obtained using an Agilent Q-TOF 6520 mass spectrometer. Absorption and emission spectra were recorded on an Edinburgh FS5 spectrofluorometer equipped with a thermostated cell holder. Fluorescence quantum yields were measured using quinine sulfate in $0.5 \mathrm{M}$ sulfuric acid $\left(\lambda_{\mathrm{ex}}=360 \mathrm{~nm}, \mathrm{QY}_{\mathrm{ref}}=\right.$ $54.6 \%)^{44}$ as a reference.

Compound $\mathbf{3 b}$ was synthesized according to known procedures. $^{45}$ Synthesis of compounds $\mathbf{1 a - 3 a}$ is based on a synthetic route, similar to one proposed previously for $\mathrm{C}$ Laurdan. ${ }^{42}$

1-(6-bromonaphthalene-2-yl)-propane-1-one (1a). $5 \mathrm{~g}$ of 2bromonaphthalene were dissolved in $25 \mathrm{~mL}$ of dry nitrobenzene under Ar atmosphere and the solution was cooled to $0{ }^{\circ} \mathrm{C}$ in an ice bath. After that, $3.56 \mathrm{~g}$ (1.1 eq.) of $\mathrm{AlCl}_{3}$ were added portionwise, followed by a dropwise addition of $2.69 \mathrm{~g}(2.54$ $\mathrm{mL}, 1.2$ equiv.) of propionyl chloride, then the reaction mixture was stirred at r.t. for 18 hours.

After the reaction the mixture was quenched with distilled water $(50 \mathrm{~mL})$ and extracted three times with EtOAc. The organic phases were combined, washed with brine, dried over $\mathrm{Na}_{2} \mathrm{SO}_{4}$ and concentrated in vacuo. The crude product was purified by recrystallization from ethanol. Yield $3.15 \mathrm{~g}(50 \%)$ as a colorless solid. ${ }^{1} \mathbf{H}$ NMR $\left(400 \mathrm{MHz}, \mathrm{CDCl}_{3}\right) \delta \mathrm{ppm} 8.43(\mathrm{~d}$, $J=1.0 \mathrm{~Hz}, 1 \mathrm{H}) 8.06(\mathrm{dd}, J=8.8,1.8 \mathrm{~Hz}, 1 \mathrm{H}) 8.04(\mathrm{~d}, J=1.5 \mathrm{~Hz}$, $1 \mathrm{H}) 7.81(\mathrm{t}, J=9.2 \mathrm{~Hz}, 2 \mathrm{H}) 7.62(\mathrm{dd}, J=8.5,2.0 \mathrm{~Hz}, 1 \mathrm{H}) 3.12$ $(\mathrm{q}, J=7.3 \mathrm{~Hz}, 2 \mathrm{H}) 1.28(\mathrm{t}, J=7.2 \mathrm{~Hz}, 3 \mathrm{H})$.

Ethyl

2-[(6-propanoylnaphthalene-2yl)methylamino]acetate (2a). An oven-dried Schlenk flask was evacuated and backfilled with Ar, after that $2 \mathrm{~g}$ of compound 1a were added together with $137 \mathrm{mg}(0.08$ equiv. $)$ of $\mathrm{Pd}(\mathrm{OAc})_{2}, 582$ $\mathrm{mg}$ ( 0.16 equiv.) of XPhos. $9.95 \mathrm{~g}$ (4 equiv.) of $\mathrm{Cs}_{2} \mathrm{CO}_{3}$ and 2.34 $\mathrm{g}$ ( 2 equiv.) of sarcosine ethyl ester (in form of hydrochloride salt). The Schlenk flask was then capped with rubber septum, evacuated and backfilled with Ar three times. After this, anhydrous dioxane $(25 \mathrm{~mL})$ was added and the mixture was stirred for $18 \mathrm{~h}$ at $100{ }^{\circ} \mathrm{C}$ under Ar atmosphere.

After the reaction the mixture was filtered through Celite and concentrated in vacuo. The crude product was purified by gradient flash column chromatography $\left(\mathrm{SiO}_{2}\right.$, Heptane:EtOAc 9:1 to $2: 8)$. Yield $1.33 \mathrm{~g} \mathrm{(58 \% )}$ as a yellow solid. ${ }^{1} \mathbf{H}$ NMR (400 $\left.\mathrm{MHz}, \mathrm{CDCl}_{3}\right) \delta \mathrm{ppm} 8.33(\mathrm{~d}, J=1.5 \mathrm{~Hz}, 1 \mathrm{H}) 7.94(\mathrm{dd}, J=8.8,1.8$ $\mathrm{Hz}, 1 \mathrm{H}) 7.80$ (d, J=9.0 Hz, $1 \mathrm{H}) 7.65$ (d, $J=8.8 \mathrm{~Hz}, 1 \mathrm{H}) 7.10$ (dd, $J=9.2,2.6 \mathrm{~Hz}, 1 \mathrm{H}) 6.89(\mathrm{~d}, J=2.5 \mathrm{~Hz}, 1 \mathrm{H}) 4.17-4.23(\mathrm{~m}$, $4 \mathrm{H}) 3.21(\mathrm{~s}, 3 \mathrm{H}) 3.08(\mathrm{q}, J=7.3 \mathrm{~Hz}, 2 \mathrm{H}) 1.27(\mathrm{t}, J=7.3 \mathrm{~Hz}, 3 \mathrm{H})$ 1.25 (t, $J=7.2 \mathrm{~Hz}, 3 \mathrm{H}) .{ }^{13} \mathbf{C ~ N M R}\left(101 \mathrm{MHz}, \mathrm{CDCl}_{3}\right) \delta \mathrm{ppm}$ $200.47\left(\mathrm{C}_{\text {carbonyl }}\right) 170.50\left(\mathrm{C}_{\text {carboxyl }}\right) 148.75\left(\mathrm{C}_{\mathrm{ar}}\right) 137.44\left(\mathrm{C}_{\mathrm{ar}}\right)$ $130.95\left(\mathrm{C}_{\mathrm{ar}}\right) 130.88\left(\mathrm{C}_{\mathrm{ar}}\right) 129.58\left(\mathrm{C}_{\mathrm{ar}}\right) 126.42\left(\mathrm{C}_{\mathrm{ar}}\right) 125.67\left(\mathrm{C}_{\mathrm{ar}}\right)$ $124.64\left(\mathrm{C}_{\mathrm{ar}}\right) 115.75\left(\mathrm{C}_{\mathrm{ar}}\right) 105.96\left(\mathrm{C}_{\mathrm{ar}}\right) 61.15\left(\mathrm{C}_{\mathrm{al}}\right) 54.43\left(\mathrm{C}_{\mathrm{al}}\right)$ $39.74\left(\mathrm{C}_{\mathrm{al}}\right) 31.52\left(\mathrm{C}_{\mathrm{al}}\right) 14.24\left(\mathrm{CH}_{3}\right) 8.64\left(\mathrm{CH}_{3}\right)$. HRMS (ESI), $m / z[\mathrm{M}+\mathrm{H}]^{+}$calcd for $\mathrm{C}_{18} \mathrm{H}_{22} \mathrm{NO}_{3}{ }^{+}, 300.1594$; found, 300.1611 .

N-methyl-N-(6-propionylnaphthalen-2-yl)glycine (3a). 1.2 $\mathrm{g}$ of compound $\mathbf{2 a}$ were dissolved in $40 \mathrm{~mL}$ of a freshly prepared solution of $\mathrm{KOH}(0.25 \mathrm{M})$ in $\mathrm{EtOH}$. The reaction mixture was 
stirred for 2 days at r. t. (control by TLC). After the reaction the solution was acidified with $\mathrm{HCl}$ to $\mathrm{pH} 2$ and the products were extracted with EtOAc three times. The ethyl acetate layers were then combined, dried over $\mathrm{Na}_{2} \mathrm{SO}_{4}$ and concentrated in vacuo. Yield 1,05 g (96\%) as a pale yellow solid. ${ }^{1} \mathbf{H}$ NMR $(400 \mathrm{MHz}$, Methanol-d 4 ) $\delta$ ppm $8.41(\mathrm{~d}, J=1.5 \mathrm{~Hz}, 1 \mathrm{H}) 7.89$ (dd, $J=8.8,1.8$ $\mathrm{Hz}, 1 \mathrm{H}) 7.86(\mathrm{~d}, J=9.3 \mathrm{~Hz}, 1 \mathrm{H}) 7.67$ (d, $J=8.5 \mathrm{~Hz}, 1 \mathrm{H}) 7.20$ (dd, J=9.0, $2.5 \mathrm{~Hz}, 1 \mathrm{H}) 6.96(\mathrm{~d}, J=2.5 \mathrm{~Hz}, 1 \mathrm{H}) 4.29(\mathrm{~s}, 2 \mathrm{H})$ 3.21 (s, $3 \mathrm{H}) 3.13$ (q, $J=7.3 \mathrm{~Hz}, 2 \mathrm{H}) 1.24$ (t, $J=7.3 \mathrm{~Hz}, 3 \mathrm{H}) .{ }^{13} \mathrm{C}$ NMR (101 MHz, Methanol-d 4 ) $\delta$ ppm 203.18 (C carbonyl $) 174.45$ $\left(\mathrm{C}_{\text {carbonyl }}\right) 150.92\left(\mathrm{C}_{\mathrm{ar}}\right) 139.32\left(\mathrm{C}_{\mathrm{ar}}\right) 132.02\left(\mathrm{C}_{\mathrm{ar}}\right) 131.75\left(\mathrm{C}_{\mathrm{ar}}\right)$ $131.30\left(\mathrm{C}_{\mathrm{ar}}\right) 127.58\left(\mathrm{C}_{\mathrm{ar}}\right) 127.01\left(\mathrm{C}_{\mathrm{ar}}\right) 125.34\left(\mathrm{C}_{\mathrm{ar}}\right) 117.20\left(\mathrm{C}_{\mathrm{ar}}\right)$ $106.70\left(\mathrm{C}_{\mathrm{ar}}\right) 54.75\left(\mathrm{C}_{\mathrm{al}}\right) 39.92\left(\mathrm{C}_{\mathrm{al}}\right) 32.44\left(\mathrm{C}_{\mathrm{al}}\right) 9.19\left(\mathrm{CH}_{3}\right)$. HRMS (ESI), $m / z[\mathrm{M}+\mathrm{H}]^{+}$calcd for $\mathrm{C}_{16} \mathrm{H}_{18} \mathrm{NO}_{3}{ }^{+}, 272.1281$; found, 272.1296.

3-(N-dodecyl-2-(methyl(6-propionylnaphthalen-2yl)amino)acetamido)propane-1-sulfonate (Pro12A). $59.5 \mathrm{mg}$ (1.05 equiv.) of 3-(dodecylamino)propane-1-sulfonate (3b) and $47.7 \mathrm{mg}(65 \mu \mathrm{L}, 2$ equiv.) of DIPEA were mixed in $2 \mathrm{~mL}$ of dry DMF under Ar atmosphere, after this the mixture was stirred for $30 \mathrm{~min}$ at $50{ }^{\circ} \mathrm{C}$. In a separate flask, $50 \mathrm{mg}$ of carboxylic acid $\mathbf{3 a}$ were dissolved in $2 \mathrm{~mL}$ of dry DMF together with $73.7 \mathrm{mg}(1.05$ equiv.) of HATU, $12.5 \mathrm{mg}$ (0.5 equiv.) of HOBt and $95.4 \mathrm{mg}$ (129 $\mu \mathrm{L}, 4$ equiv.) of DIPEA. After 5 minutes, the solution of activated acid was transferred to the flask with amine and the final mixture was stirred for $24 \mathrm{~h}$ at $45^{\circ} \mathrm{C}$ (control by TLC). After the reaction the solvent was evaporated in vacuo and the crude product was purified by preparative TLC $\left(\mathrm{SiO}_{2}\right.$; DCM:MeOH 85:15). Compound Pro12A: yield $104 \mathrm{mg}$ (82 \%) as pale yellow solid (obtained in form of a salt with DIPEA). ${ }^{1} \mathbf{H}$ NMR (400 MHz, Methanol- $\left.d_{4}\right) \delta$ ppm $8.37(\mathrm{~s}, 1 \mathrm{H}) 7.86$ (ddd, $J=8.8,3.2$, $1.7 \mathrm{~Hz}, 1 \mathrm{H}) 7.81(\mathrm{dd}, J=9.0,2.5 \mathrm{~Hz}, 1 \mathrm{H}) 7.63(\mathrm{dd}, J=8.8,5.5$ $\mathrm{Hz}, 1 \mathrm{H}) 7.13(\mathrm{td}, J=9.4,2.5 \mathrm{~Hz}, 1 \mathrm{H}) 6.88(\mathrm{t}, J=3.0 \mathrm{~Hz}, 1 \mathrm{H})$ $4.43(\mathrm{~d}, J=31.6 \mathrm{~Hz}, 2 \mathrm{H}) 3.54(\mathrm{dt}, J=41.9,8.0 \mathrm{~Hz}, 2 \mathrm{H}) 3.34$ $3.42(\mathrm{~m}, 2 \mathrm{H}) 3.13-3.21(\mathrm{~m}, 5 \mathrm{H}) 2.79-2.96(\mathrm{~m}, 2 \mathrm{H}) 1.99$ $2.21(\mathrm{~m}, 2 \mathrm{H}) 1.51-1.73(\mathrm{~m}, 2 \mathrm{H}) 1.18-1.31(\mathrm{~m}, 21 \mathrm{H}) 0.85-$ $0.90(\mathrm{~m}, 3 \mathrm{H}) .{ }^{13} \mathbf{C}$ NMR (101 MHz, Methanol-d 4 ) $\delta$ ppm 203.00 (d, J=5.8 Hz, C carboxyl $) 171.44\left(\mathrm{C}_{\text {carboxyl }}\right) 151.27(\mathrm{~d}, J=15.8 \mathrm{~Hz}$, $\left.\mathrm{C}_{\mathrm{ar}}\right) 139.34\left(\mathrm{C}_{\mathrm{ar}}\right) 139.30\left(\mathrm{C}_{\mathrm{ar}}\right) 131.96\left(\mathrm{~d}, J=10.2 \mathrm{~Hz}, \mathrm{C}_{\mathrm{ar}}\right) 131.55$ (d, J=13.3 Hz, C $\mathrm{Car}) 131.32\left(\mathrm{C}_{\mathrm{ar}}\right) 127.53$ (d, J=3.3 Hz, $\left.\mathrm{C}_{\mathrm{ar}}\right) 126.84$ $\left(\mathrm{d}, J=8.5 \mathrm{~Hz}, \mathrm{C}_{\mathrm{ar}}\right) 125.31\left(\mathrm{~d}, J=12.4 \mathrm{~Hz}, \mathrm{C}_{\mathrm{ar}}\right) 117.37$ (d, $J=10.2$ $\left.\mathrm{Hz}, \mathrm{C}_{\mathrm{ar}}\right) 106.62\left(\mathrm{C}_{\mathrm{ar}}\right) 55.96\left(\mathrm{C}_{\mathrm{al}}\right) 54.97\left(\mathrm{~d}, J=12.0 \mathrm{~Hz}, \mathrm{C}_{\mathrm{al}}\right) 47.13$ $\left(\mathrm{d}, J=18.7 \mathrm{~Hz}, \mathrm{C}_{\mathrm{al}}\right) 40.13\left(\mathrm{~d}, J=22.6 \mathrm{~Hz}, \mathrm{C}_{\mathrm{al}}\right) 33.20\left(\mathrm{C}_{\mathrm{al}}\right) 32.41$ $\left(\mathrm{C}_{\mathrm{al}}\right) 30.82-30.96\left(\mathrm{~m}, \mathrm{C}_{\mathrm{al}}\right) 30.58-30.66\left(\mathrm{~m}, \mathrm{C}_{\mathrm{al}}\right) 30.01\left(\mathrm{C}_{\mathrm{al}}\right)$ $28.86\left(\mathrm{C}_{\mathrm{al}}\right) 28.15\left(\mathrm{~d}, J=7.9 \mathrm{~Hz}, \mathrm{C}_{\mathrm{al}}\right) 25.68\left(\mathrm{C}_{\mathrm{al}}\right) 23.86\left(\mathrm{C}_{\mathrm{al}}\right) 14.58$ $\left(\mathrm{C}_{\mathrm{al}}\right) 13.28\left(\mathrm{CH}_{3}\right) 9.22\left(\mathrm{CH}_{3}\right)$. HRMS (ESI), $\mathrm{m} / \mathrm{z}:[\mathrm{M}+2 \mathrm{Na}]^{+}$ calcd for $\mathrm{C}_{31} \mathrm{H}_{47} \mathrm{~N}_{2} \mathrm{O}_{5} \mathrm{SNa}_{2}, 605.3011$; found, 605.3015.

Preparation of large unilamellar vesicles (LUVs). All types of LUVs used were prepared by the following procedure. A stock solution of corresponding lipid(s) in chloroform was placed into a round-neck flask, after which the solvent was evaporated in vacuo and phosphate buffer $(20 \mathrm{mM}, \mathrm{pH} 7.4)$ was added. After all the solid was dissolved a suspension of multilamellar vesicles was extruded by using a Lipex Biomembranes extruder (Vancouver, Canada). The size of the filters was first $0.2 \mu \mathrm{m}$ (7 passages) and thereafter $0.1 \mu \mathrm{m}$ (10 passages). This generates monodisperse LUVs with a mean diameter of $0.12 \mu \mathrm{m}$ as measured with a Malvern Zetamaster 300 (Malvern, U.K.). Phospholipid:Cholesterol molar ratio in case of DOPC/Chol and SM/Chol was 1:0.9. LUVs were labelled by addition of the DMSO stock solution of the probes to a final concentration $2 \mu \mathrm{M}$, unless indicated and incubation for $5 \mathrm{~min}$.

Fluorescence quenching experiment. Solutions of Pro12A and Laurdan in DOPC LUVs $(1 \mu \mathrm{M}$ of dye for $500 \mu \mathrm{M}$ total lipid concentration) were made by adding concentrated dye stock solution in DMSO to LUVs followed by vortexing the mixture. In case of Pro12A, the mixture was incubated for $15 \mathrm{~min}$ at RT. To ensure complete binding and disaggregation of Laurdan, brief heating to $40{ }^{\circ} \mathrm{C}$ was done, followed by another vortexing and slow cooling over $2 \mathrm{~h}$. Then, Violgen-C12 was added (from DMSO stock solution) to a given concentration and fluorescence spectra were measured after 15 min incubation.

Preparation of giant unilamellar vesicles (GUVs). GUVs were prepared by electroformation. Lipid stock (DOPC:SM:Chol 2:2:1) was spread onto two parallel platinum wires attached to a custom-built Teflon-coated chamber and left briefly to evaporate the solvent. Wires were passed under nitrogen gas before submersion in $300 \mathrm{mM}$ sucrose. $10 \mathrm{~Hz}$ AC current was applied for 1 hour to trigger vesicles swelling at 70 ${ }^{\circ} \mathrm{C}$, followed by $2 \mathrm{~Hz}$ for 30 minutes with slow cooling.

Preparation of giant plasma membrane vesicles (GPMVs). GPMVs were prepared as previously described. ${ }^{46}$ Briefly, cells seeded out on a $60 \mathrm{~mm}$ petri dish $(\approx 70 \%$ confluent $)$ were washed with GPMV buffer (150 mM NaCl, $10 \mathrm{mM}$ Hepes, $2 \mathrm{mM} \mathrm{CaCl}_{2}$, $\mathrm{pH} 7.4$ ) twice. $2 \mathrm{~mL}$ of GPMV buffer was added to the cells. 25 mM PFA and $20 \mathrm{mM}$ DTT (final concentrations) were added in the GPMV buffer. The cells were incubated for $2 \mathrm{~h}$ at $37^{\circ} \mathrm{C}$. Then, GPMVs were collected by pipetting out the supernatant. GUVs and GPMVs were labelled by adding Pro12A (or Laurdan and C-Laurdan) with a final concentration of $50 \mathrm{nM}$.

Cell Lines, Culture Conditions, and Treatment. CHO cells were maintained in DMEM-F12 medium supplemented with $10 \%$ FBS medium and 1\% L-glutamine. Cells were transfected with the plasmids using Lipofectamine 3000 as described in manufacturer's protocol.

Fluorescence microscopy. All imaging was done at room temperature $\left(21-23^{\circ} \mathrm{C}\right)$. Samples were imaged with a Zeiss LSM 780 confocal microscope. Spectral imaging was done as described before. ${ }^{47}$ Cells were incubated with Pro12A (or Laurdan and C-Laurdan) with a final concentration of $0.8 \mu \mathrm{M}$ in PBS for 5 minutes. After the labelling, the cells were washed once and the imaging was performed in L15 medium. Pro12A, Laurdan and C-Laurdan were excited with $405 \mathrm{~nm}$ and emission collected between 410-600 $\mathrm{nm}$.

\section{RESULTS AND DISCUSSION}

The probe Pro12A was designed based on solvatochromic fluorophore Prodan (parent analogue of Laurdan) ${ }^{34}$ and the anionic plasma membrane targeting moiety (Figure 1, A). The latter is composed of lipophilic dodecyl chain and anionic sulfonate, which ensure effective high-affinity binding to cell plasma membranes. ${ }^{39}$ The solvatochromic dye is expected to sense changes in lipid order in plasma membrane by changing its emission color (Figure 1, B): shifting its emission to the longer wavelengths (e.g. from green to orange) from apolar dehydrated Lo phase to polar hydrated Ld phase. ${ }^{2}$ Taking into account that charged carboxylate did not decrease sensitivity of C-Laurdan to lipid order compared to parent Laurdan, ${ }^{36}$ we functionalized this fluorophore at the dialkylamino side. The synthesis was performed in 4 steps starting from 2- 
bromonaphthalene (Figure 1, C). At the final step, the key intermediate, a Prodan bearing carboxylate group (3a), was coupled to the anchor-amine (3b), affording the final probe Pro12A with a relatively good yield. The structure of new compounds was confirmed by NMR and Mass spectroscopy (SI Figure S1-S9).

Absorption and fluorescence spectroscopy of Pro12A in organic solvents showed that it preserved solvatochromism of parent Laurdan (Table S1, Figure 2, A, SI Figure S10, C-D). Indeed, similarly to Laurdan, Pro12A displayed a red shift in fluorescence spectra with increase in the solvent polarity. Large unilamellar vesicles (LUVs) with different phospholipid composition were then used as model membranes, presenting Ld phase in case of unsaturated lipid DOPC with or without cholesterol and Lo phase for a mixture of sphingomyelin (SM) and cholesterol. Emission band of Pro12A in the Lo phase (Figure 2, B, Figure S10, A-B) was strongly blue shifted with respect to that of the Ld phase without cholesterol, in line with that for Laurdan and other solvatochromic dyes. ${ }^{39,48}$ Interestingly, the value of blue shift from Ld (DOPC) to Lo (SM/Chol) phase was slightly larger for Pro12A compared to Laurdan (59 vs $53 \mathrm{~nm}$, see Tab. S1). Similar to Laurdan, the Pro12A probe can also sense presence of cholesterol in DOPC vesicles (Table $\mathrm{S} 1$ ), so that the resulting spectrum is intermediate between those in SM/Chol and DOPC LUVs (Figure 2, B). The absorption maximum of Pro12A in LUVs was systematically red shifted (372-379 nm) compared to Laurdan (356-358 nm), making it more suitable for excitation with common violet light sources (395 nm LED or $405 \mathrm{~nm}$ laser). Moreover, the new probe in LUVs exhibited 2-3-fold larger fluorescence quantum yield (QY) values compared to Laurdan (Table S1). This drastic difference is probably linked to the more efficient membrane binding of Pro12A. The amphiphilic nature of our probe, induced by the charged sulfonate group, renders its better solubilization in water and further transfer to lipid membranes, whereas a highly hydrophobic Laurdan could partially precipitate in aqueous buffer before reaching the lipid membrane. Fluorescence intensity of Pro12A in buffer increased linearly with concentration until $0.5 \mu \mathrm{M}$, followed by the decrease the slope of the titration curve (SI Figure S11). This observation suggests the presence of critical micellar concentration $(\mathrm{CMC} \sim 0.5 \mu \mathrm{M})$ for Pro12A, above which the dye molecules undergo self-quenching. The latter is useful for decreasing the background fluorescence of the free probes in solution, similarly to other amphiphilic membrane probes. ${ }^{33,39,43}$
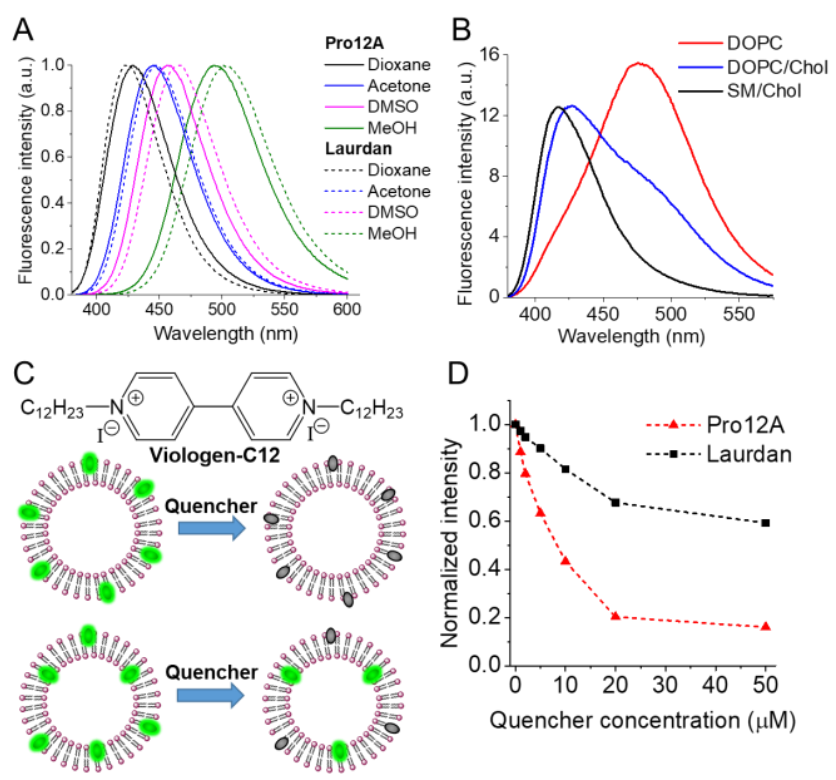

Figure 2. Spectroscopy experiments in solvents and lipid vesicles. (A) Normalized fluorescence spectra of Pro12A and Laurdan in solvents of different polarity. (B) Fluorescence spectra of Pro12A in LUVs of different composition. Probe concentration was systematically $2 \mu \mathrm{M}$. Total lipid concentration for all vesicles was 1 $\mathrm{mM}$. (C) Chemical structure of Viologen-C12 and scheme of surface quenching by Viologen-C12 of the probes located at the outer bilayer leaflet (upper panel) and both leaflets (lower panel). (D) Fluorescence quenching of Pro12A and Laurdan in DOPC LUVs by increasing concentrations of Violgen-C12. The intensity was recorded at the maximum of probe emission: $476 \mathrm{~nm}$ (Pro12A) and $493 \mathrm{~nm}$ (Laurdan). Probe and lipid concentrations were 1 and 500 $\mu \mathrm{M}$, respectively. $20 \mathrm{mM}$ phosphate buffer ( $\mathrm{pH}$ 7.4) was used for all LUVs. $\lambda_{\mathrm{ex}}=360 \mathrm{~nm}$ in all cases.

The probe added to the bulk solution is expected to bind first to the outer membrane leaflet and remain there if it does not undergo a flip-flop. ${ }^{33}$ To verify the localization of Pro12A at the outer membrane leaflet, we used fluorescence quenching by photoinduced electron transfer $(\mathrm{PET})^{49}$ with a specially designed amphiphilic dodecyl viologen (Violgen-C12, Figure 2, C). Due to their highly electron-deficient nature, viologens are efficient PET quenchers, ${ }^{50-52}$ while dodecyl chains should provide the quencher with high affinity to lipid membranes. As PET process requires a close dye-quencher proximity ${ }^{53}$ only the dye at the outer leaflet is expected to be effectively quenched by ViologenC12 (Figure 2, C). Fluorescence intensity of Pro12A in DOPC LUVs dropped rapidly with Viologen-C12 concentration increase, reaching $84 \%$ quenching at $50 \mu \mathrm{M}$ concentration, whereas only $41 \%$ quenching was observed for Laurdan (Figure 2, D; Figure S10, E-F). The shape of the curves with saturation behavior at higher quencher concentrations was similar for both probes, indicating that the binding mode of Violgen-C12 is similar for both probes and the difference in the quenching efficiency is linked to different availability of the probe to the quencher. We can conclude that Pro12A is much more exposed to the quencher, probably because it is localized at the outer leaflet, in contrast to Laurdan that can diffuse freely through the membrane to the inner leaflet. Thus, the use of anchor group 
favors one-leaflet binding, as it is expected to inhibit the flipflop between the leaflets.

Next, we tested Pro12A in phase separated membrane systems. In microscopy experiments with phase separated giant unilamellar vesicles (GUVs) and giant plasma membrane vesicles (GPMVs), ${ }^{46}$ Pro12A was able to distinguish the domains with different lipid order (Figure 3). Spectroscopic scan of the vesicles labeled by Pro12A revealed different intensity variation as a function of the wavelength (Figure 3, A). The reconstructed spectra for each region in GUVs revealed a strong band shift (Figure 3, B), with band positions corresponding to those in Lo and Ld phases of LUVs (Fig 2, B). The spectral change in GPMVs was similar (Figure 3, C), but its amplitude was smaller as expected given the packing of the domains is less different compared to GUVs. ${ }^{54}$ Then, ratiometric imaging using

A

$415 \quad$ wavelength $(\mathrm{nm})$
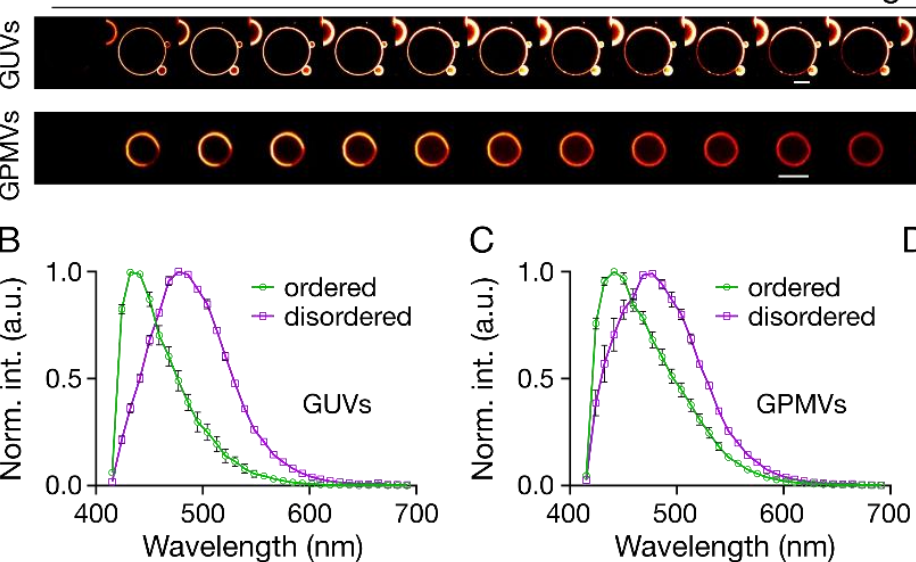

D
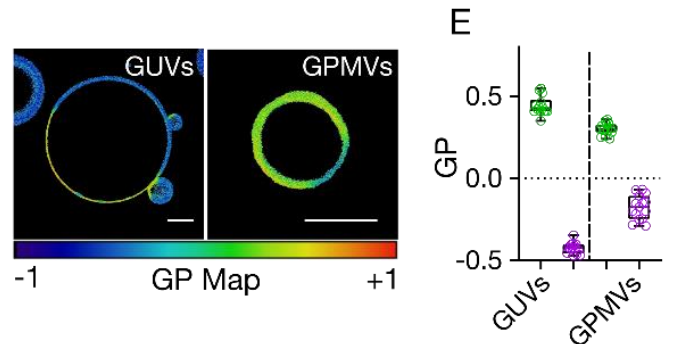

Figure 3. Spectra of Pro12A in phase separated GUVs and GPMVs. A) Montage of spectral images obtained with spectral detector (each image is one channel with $8.9 \mathrm{~nm}$ wavelength intervals) for Pro12A-doped GUVs and GPMVs. B, C) Reconstruction of spectra from the spectral images for B) GUVs and C) GPMVs. D) GP images of phase separated GUVs and GPMVs. E) GP values obtained from phase separated GUVs and GPMVs. Scale bars are $10 \mu \mathrm{m}$.

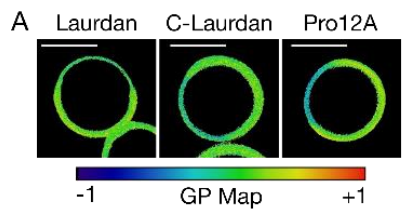

B
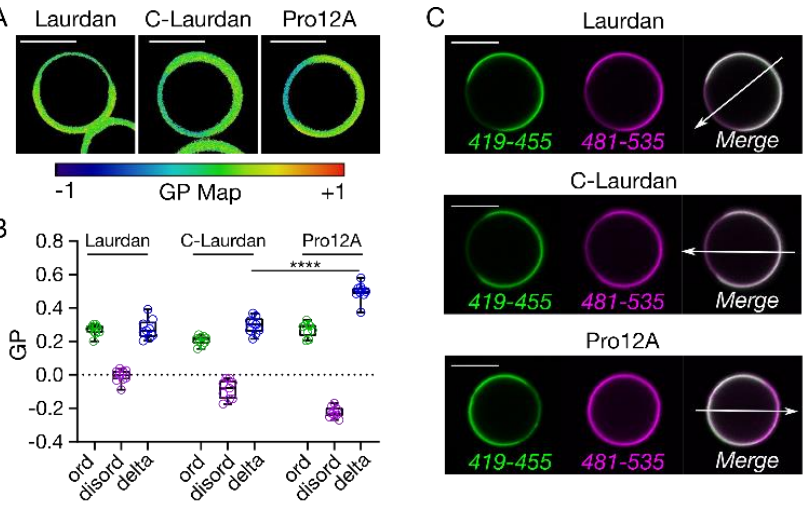

Pro12A
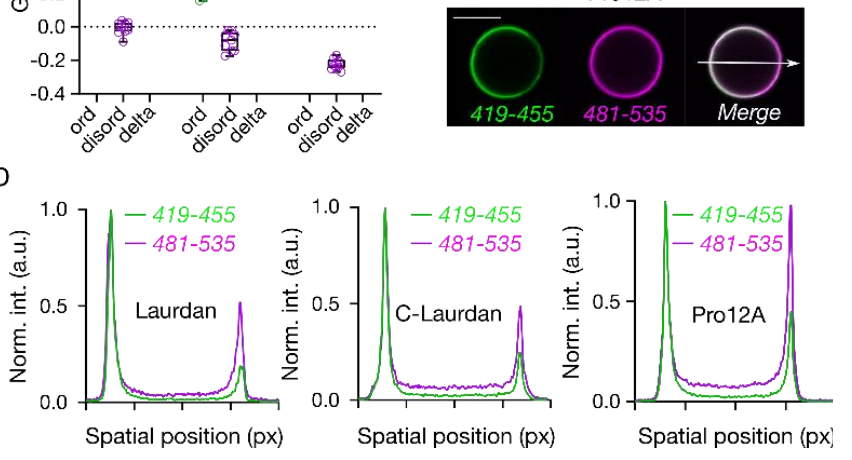

Figure 4. Sensitivity of Pro12A, Laurdan and C-Laurdan to lipid packing in phase separated GPMVs A) GP images of GPMVs doped with Laurdan, C-Laurdan and Pro12A. B) Quantification of GP for the ordered and disordered phases obtained from GPMVs stained with Laurdan, C-Laurdan and Pro12A. C) Fluorescence signal in the ordered vs disordered channel for these three probes. D) Line profiles of fluorescence signal in the ordered and disordered phases and in the ordered and disordered channels.

On the next step, we compared Pro12A with Laurdan and CLaurdan probes in phase separated GPMVs (Figure 4) in terms of sensitivity to lipid order. GP images and the obtained values (Figure 4, A-B) suggested that Pro12A is more sensitive to changes in lipid order in GPMVs compared to its counterparts. Additionally, Pro12A displayed almost equal fluorescence signal from the two separated lipid phases (Figure 4, C-D). By contrast, Laurdan and C-Laurdan showed significantly lower signal in Ld phase of GPMVs compared to Lo, in line with previous reports. ${ }^{47,55}$ Even partitioning of Pro12A between Lo and Ld phases is another important advantage, because it allows recording good signal from both domains while distinguishing them by emission color.

Next, we compared these three probes in terms of internalization. Confocal imaging of live Chinese Hamster 
Ovary (CHO) cells stained with Pro12A showed strong fluorescence signal at the plasma membranes and practically complete absence of the signal inside the cells 15 minutes after the labelling (Figure 5, A). In sharp contrast, Laurdan and especially C-Laurdan showed significant fluorescence signal inside the cells and thus much less resolved membrane signal (Figure 5, B-C). These observations were further supported by plotting the signal intensity (line profile) across the cellular membrane (Figure 5, D), revealing that only Pro12A showed nearly zero signal both outside and inside the cells, while CLaurdan showed the strongest intracellular fluorescence. Thus,

A

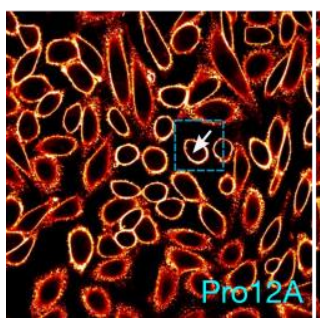

B

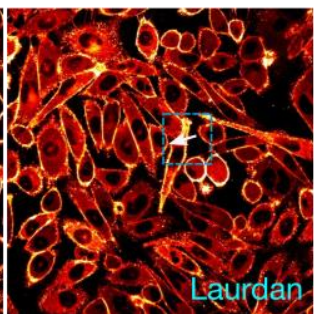

C

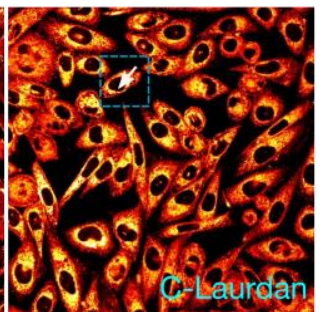

the presence of the membrane anchor with sulfonate group and dodecyl chain ensures effective plasma membrane targeting of the dye. The observed stronger internalization of C-Laurdan compared to Laurdan is unexpected and it could be explained by its better water solubility and thus stronger partitioning into cells when used at the same concentration.

Figure 5. Internalization of Pro12A, Laurdan and C-Laurdan in live cells. Confocal microcopy images of CHO cells stained with Pro12A (A), Laurdan (B) and C-Laurdan (C). Fluorescence intensity plots across the cell membranes (D) in the highlighted regions of A-C. Response of Pro12A and Laurdan to methyl- $\beta$-cyclodextrin treatment (E).

After that, the ability of Pro12A and Laurdan to respond to changes in cholesterol content in live cell plasma membrane was tested using cholesterol extraction by methyl- $\beta$-cyclodextrin ${ }^{56}$ (MCBD) (Figure 5, E). For both probes, cholesterol extraction decreased the GP values, which is expected because lower cholesterol content decreases lipid order. ${ }^{35}$ Remarkably, Pro12A displayed much stronger decrease in the GP values compared to Laurdan (Figure 5, E). The observed higher sensitivity of Pro12A vs Laurdan to cholesterol extraction is probably related to the differences in the leaflet binding behavior of these two probes. Laurdan is distributed between the both membrane leaflets, while Pro12A is expected to localize only at the outer one, which is supported by our quenching experiments (Figure 2, C-D). As the outer leaflet of plasma membrane is richer in sphingomyelin ${ }^{26,28}$ and probably in cholesterol ${ }^{57}$ than the inner one, cholesterol extraction should produce stronger changes in the lipid order at the outer leaflet. Therefore, Pro12A localized at this leaflet surpasses Laurdan that provides an averaged signal from both leaflets. 

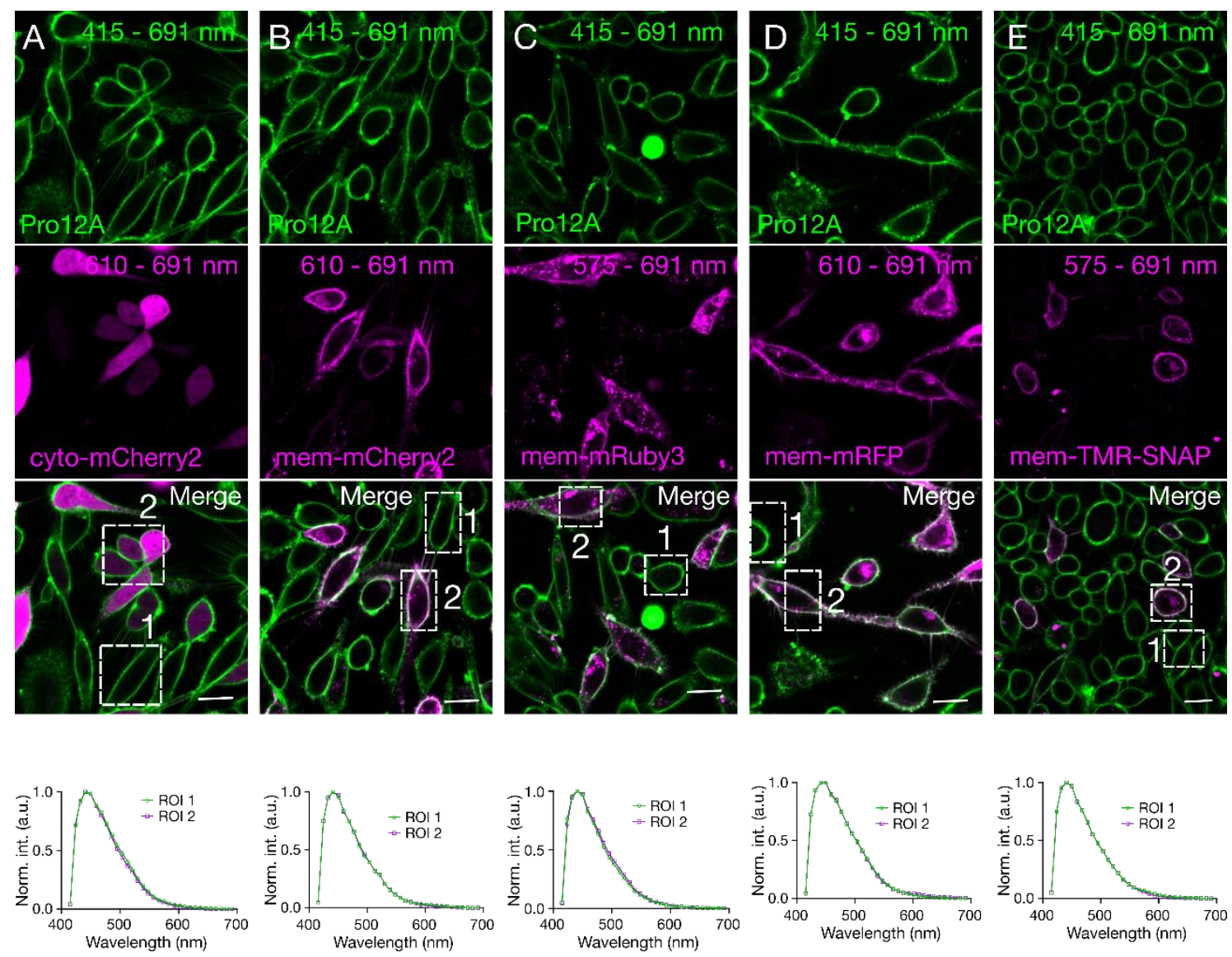

Figure 6. Application of Pro12A in combination with fluorescent proteins. Images of cells labelled with Pro12A and transfected with: A) cytosolic mCherry2; B) membrane-anchored mCherry2; C) membrane-anchored mRuby3; D) membrane-anchored mRFP; E) membraneanchored TMR. Top panels are images and bottom panels are intensity profiles of the regions marked in the corresponding images. Two separate region of interest (ROI) are selected; in ROI 1, there is only Pro12A signal (no protein), while in ROI 2, there is both protein and Pro12A signal. Two ROIs possess identical spectra, showing no effect of these fluorescent proteins on Pro12A spectrum. Scale bars: $10 \mu \mathrm{m}$.

Finally, the compatibility of Pro12A with commonly used fluorescent proteins or dyes was examined using fluorescence microscopy in live $\mathrm{CHO}$ cells (Fig 6). mCherry2 localized in cytosol (Figure 6, A) and membrane (Figure 6, B), membranelocalized mRuby (Figure 6, C), mRFP (Figure 6, D) and TMRSNAP (Figure 6, E) were imaged in cells co-stained with Pro12A using respective detection channels. It was found that the emission spectrum of Pro12A in cells acquired by a microscope does not alter in case of all these co-staining conditions (Fig 6, A-E), which signifies an absence of signal leakage and high compatibility of ProA 12 with all the fluorescent proteins and dyes studied.

\section{CONCLUSIONS}

In order to develop a universal tool for monitoring lipid organization of cell plasma membranes, compatible with common fluorescent proteins, we addressed the fundamental drawback of a well-known solvatochromic probe Laurdan for sensing lipid order, related to its internalization and inefficient plasma membrane labelling. We redesigned Laurdan by grafting an anchor group composed of sulfonate charged group and dodecyl alkyl chain. The new probe Pro12A showed 2-3-fold higher fluorescence quantum yields in lipid membranes because of more effective partitioning from aqueous medium. It also shows higher sensitivity to lipid order in both model lipid vesicles and membranes derived from cells, probably because of more defined localization in lipid membranes imposed by anchor group. Finally, in contrast to Laurdan, Pro12A binds exclusively the outer membrane leaflet and stains selectively cell plasma membranes without detectable internalization. Due to this specific outer leaflet targeting, the sensitivity of ProA12 to cholesterol extraction from plasma membranes of live cells is much higher compared to that of Laurdan. Its application in combination with commonly used orange/red fluorescent proteins and dyes revealed an absence of signal cross-talk, allowing for accurate and unbiased multicolor cellular microscopy. This probe reinforces the toolkit of available solvatochromic membrane probes, opening new possibilities for biomembrane imaging in live cells.

\section{ASSOCIATED CONTENT}

\section{Supporting Information}


The Supporting Information is available free of charge on the ACS Publications website. It describes the probe synthesis and characterization and additional spectroscopy data, as well as additional experimental data.

\section{AUTHOR INFORMATION}

\section{CorrespondingAuthor}

Andrey S. Klymchenko - Laboratoire de Bioimagerie et Pathologies, UMR 7021 CNRS, Université de Strasbourg,67401 Illkirch, France; orcid.org/0000-0002-2423-830X;

Email: andrey.klymchenko@unistra.fr

\section{Authors}

Dmytro I. Danylchuk-Laboratoire de Bioimagerie et Pathologies, UMR 7021 CNRS, Université de Strasbourg, 67401 Illkirch, France. Erdinc Sezgin- Science for Life Laboratory, Department of Women's and Children's Health, Karolinska Institutet, Stockholm, Sweden

Philippe Chabert-Laboratoire de Bioimagerie et Pathologies, UMR 7021 CNRS, Université de Strasbourg, 67401 Illkirch, France.

\section{Author Contributions}

The manuscript was written through contributions of all authors. All authors have given approval to the final version of the manuscript. $\$$ These authors contributed equally.

\section{Notes}

The authors declare no competing financial interest.

\section{ACKNOWLEDGMENT}

This work was supported by the European Research Council ERC Consolidator grant BrightSens 648528 and ED222 of University of Strasbourg. ES is supported by SciLifeLab fellow program.

\section{REFERENCES}

(1) Sezgin, E.; Levental, I.; Mayor, S.; Eggeling, C. The mystery of membrane organization: composition, regulation and roles of lipid rafts. Nat. Rev. Mol. Cell Biol. 2017, 18, 361374.

(2) Klymchenko, A. S.; Kreder, R. Fluorescent Probes for Lipid Rafts: From Model Membranes to Living Cells. Chem. Biol. 2014, 21, 97-113.

(3) Wang, H. M.; Feng, Z. Q. Q.; Del Signore, S. J.; Rodal, A. A.; Xu, B. Active Probes for Imaging Membrane Dynamics of Live Cells with High Spatial and Temporal Resolution over Extended Time Scales and Areas. J. Am. Chem. Soc. 2018, 140, 3505-3509.

(4) Bumpus, T. W.; Baskin, J. M. Greasing the Wheels of Lipid Biology with Chemical Tools. Trends Biochem. Sci. 2018, 43, 970-983.

(5) Stone, M. B.; Shelby, S. A.; Veatch, S. L. Super-Resolution Microscopy: Shedding Light on the Cellular Plasma Membrane. Chem. Rev. 2017, 117, 7457-7477.

(6) Klymchenko, A. S. Solvatochromic and Fluorogenic Dyes as Environment-Sensitive Probes: Design and Biological Applications. Acc. Chem. Res. 2017, 50, 366-375.
(7) Chambers, J. E.; Kubankova, M.; Huber, R. G.; LopezDuarte, I.; Avezov, E.; Bond, P. J.; Marciniak, S. J.; Kuimova, M. K. An Optical Technique for Mapping Microviscosity Dynamics in Cellular Organelles. ACS Nano 2018, 12, 43984407.

(8) Su, D. D.; Teoh, C. L.; Wang, L.; Liu, X. G.; Chang, Y. T. Motion-induced change in emission (MICE) for developing fluorescent probes. Chem. Soc. Rev. 2017, 46, 4833-4844.

(9) Sherin, P. S.; Lopez-Duarte, I.; Dent, M. R.; Kubankova, M.; Vysniauskas, A.; Bull, J. A.; Reshetnikova, E. S.;

Klymchenko, A. S.; Tsentalovich, Y. P.; Kuimova, M. K. Visualising the membrane viscosity of porcine eye lens cells using molecular rotors. Chem. Sci. 2017, 8, 3523-3528.

(10) Colom, A.; Derivery, E.; Soleimanpour, S.; Tomba, C.; Dal Molin, M.; Sakai, N.; Gonzalez-Gaitan, M.; Matile, S.; Roux, A. A fluorescent membrane tension probe. Nat. Chem. 2018, 10, 1118-1125.

(11) Dal Molin, M.; Verolet, Q.; Colom, A.; Letrun, R.; Derivery, E.; Gonzalez-Gaitan, M.; Vauthey, E.; Roux, A.; Sakai, N.; Matile, S. Fluorescent Flippers for Mechanosensitive Membrane Probes. J. Am. Chem. Soc. 2015, 137, 568-571.

(12) Demchenko, A. P.; Mely, Y.; Duportail, G.; Klymchenko, A. S. Monitoring Biophysical Properties of Lipid Membranes by Environment-Sensitive Fluorescent Probes. Biophys. $J$. 2009, 96, 3461-3470.

(13) Shynkar, V. V.; Klymchenko, A. S.; Kunzelmann, C.; Duportail, G.; Muller, C. D.; Demchenko, A. P.; Freyssinet, J. M.; Mely, Y. Fluorescent biomembrane probe for ratiometric detection of apoptosis. J. Am. Chem. Soc. 2007, 129, 21872193.

(14) Kreder, R.; Pyrshev, K. A.; Darwich, Z.; Kucherak, O. A.; Mely, Y.; Klymchenko, A. S. Solvatochromic Nile Red probes with FRET quencher reveal lipid order heterogeneity in living and apoptotic cells. ACS Chem. Biol. 2015, 10, 1435-1442. (15) Liu, C.; Tian, M. G.; Lin, W. Y. A unique polaritysensitive photothermal sensitizer revealing down-regulated mitochondrial polarity during photo-induced cell death. $J$. Mater. Chem. B 2020, 8, 752-757.

(16) Ashoka, A. H.; Ashokkumar, P.; Kovtun, Y. P.; Klymchenko, A. S. Solvatochromic Near-Infrared Probe for Polarity Mapping of Biomembranes and Lipid Droplets in Cells under Stress. J. Phys. Chem. Lett. 2019, 10, 2414-2421.

(17) Han, X. Y.; Wang, R.; Song, X. Y.; Yu, F. B.; Lv, C. J.; Chen, L. X. A mitochondrial-targeting near-infrared fluorescent probe for bioimaging and evaluating endogenous superoxide anion changes during ischemia/reperfusion injury. Biomaterials 2018, 156, 134-146.

(18) de la Haba, C.; Palacio, J. R.; Martinez, P.; Morros, A. Effect of oxidative stress on plasma membrane fluidity of THP1 induced macrophages. Biochim. Biophys. Acta Biomembr. 2013, 1828, 357-364.

(19) Jiang, N.; Fan, J. L.; Xu, F.; Peng, X. J.; Mu, H. Y.; Wang, J. Y.; Xiong, X. Q. Ratiometric Fluorescence Imaging of Cellular Polarity: Decrease in Mitochondrial Polarity in Cancer Cells. Angew. Chem. Int. Ed. Engl. 2015, 54, 2510-2514.

(20) Lingwood, D.; Simons, K. Lipid Rafts As a MembraneOrganizing Principle. Science 2010, 327, 46-50.

(21) Simons, K.; Ikonen, E. Functional rafts in cell membranes. Nature 1997, 387, 569-572. 
(22) Brown, D. A.; London, E. Structure and function of sphingolipid- and cholesterol-rich membrane rafts. J. Biol. Chem. 2000, 275, 17221-17224.

(23) Dietrich, C.; Bagatolli, L. A.; Volovyk, Z. N.; Thompson, N. L.; Levi, M.; Jacobson, K.; Gratton, E. Lipid rafts reconstituted in model membranes. Biophys. J. 2001, 80, $1417-$ 1428 .

(24) Veatch, S. L.; Keller, S. L. Separation of liquid phases in giant vesicles of ternary mixtures of phospholipids and cholesterol. Biophys. J. 2003, 85, 3074-3083.

(25) Baumgart, T.; Hess, S. T.; Webb, W. W. Imaging coexisting fluid domains in biomembrane models coupling curvature and line tension. Nature 2003, 425, 821-824. (26) Zwaal, R. F. A.; Schroit, A. J. Pathophysiologic implications of membrane phospholipid asymmetry in blood cells. Blood 1997, 89, 1121-1132.

(27) Murate, M.; Abe, M.; Kasahara, K.; Iwabuchi, K.; Umeda, M.; Kobayashi, T. Transbilayer distribution of lipids at nano scale. J. Cell Sci. 2015, 128, 1627-1638.

(28) Lorent, J. H.; Levental, K. R.; Ganesan, L.; RiveraLongsworth, G.; Sezgin, E.; Doktorova, M.; Lyman, E.; Levental, I. Plasma membranes are asymmetric in lipid unsaturation, packing and protein shape. Nat. Chem. Biol. 2020, 16, 644-652.

(29) Wu, Y. L.; Stefl, M.; Olzynska, A.; Hof, M.; Yahioglu, G.; Yip, P.; Casey, D. R.; Ces, O.; Humpolickova, J.; Kuimova, M. $\mathrm{K}$. Molecular rheometry: direct determination of viscosity in L$\mathrm{o}$ and L-d lipid phases via fluorescence lifetime imaging. Phys. Chem. Chem. Phys. 2013, 15, 14986-14993.

(30) Amaro, M.; Reina, F.; Hof, M.; Eggeling, C.; Sezgin, E. Laurdan and Di-4-ANEPPDHQ probe different properties of the membrane. J. Phys. D Appl. Phys. 2017, 50, 134004. (31) Zhang, Y. L.; Frangos, J. A.; Chachisvilis, M. Laurdan fluorescence senses mechanical strain in the lipid bilayer membrane. Biochem. Biophys. Res. Commun. 2006, 347, 838841.

(32) Bagatolli, L. A. To see or not to see: Lateral organization of biological membranes and fluorescence microscopy. Biochim. Biophys. Acta Biomembr. 2006, 1758, 1541-1556. (33) Kucherak, O. A.; Oncul, S.; Darwich, Z.; Yushchenko, D. A.; Arntz, Y.; Didier, P.; Mely, Y.; Klymchenko, A. S. Switchable Nile Red-Based Probe for Cholesterol and Lipid Order at the Outer Leaflet of Biomembranes. J. Am. Chem. Soc. 2010, 132, 4907-4916.

(34) Weber, G.; Farris, F. J. Synthesis and Spectral Properties of a Hydrophobic Fluorescent-Probe - 6-Propionyl-2-

(Dimethylamino)Naphthalene. Biochemistry 1979, 18, 30753078.

(35) Owen, D. M.; Rentero, C.; Magenau, A.; Abu-Siniyeh, A.; Gaus, K. Quantitative imaging of membrane lipid order in cells and organisms. Nat. Protoc. 2012, 7, 24-35.

(36) Kim, H. M.; Choo, H. J.; Jung, S. Y.; Ko, Y. G.; Park, W. H.; Jeon, S. J.; Kim, C. H.; Joo, T.; Cho, B. R. A two-photon fluorescent probe for lipid raft imaging: C-laurdan. ChemBioChem 2007, 8, 553-559.

(37) Jin, L.; Millard, A. C.; Wuskell, J. P.; Dong, X. M.; Wu, D. Q.; Clark, H. A.; Loew, L. M. Characterization and application of a new optical probe for membrane lipid domains. Biophys. J. 2006, 90, 2563-2575.

(38) Bongiovanni, M. N.; Godet, J.; Horrocks, M. H.; Tosatto, L.; Carr, A. R.; Wirthensohn, D. C.; Ranasinghe, R. T.; Lee, J.
E.; Ponjavic, A.; Fritz, J. V.; Dobson, C. M.; Klenerman, D.; Lee, S. F. Multi-dimensional super-resolution imaging enables surface hydrophobicity mapping. Nat. Commun. 2016, 7, 9. (39) Danylchuk, D. I.; Moon, S.; Xu, K.; Klymchenko, A. S. Switchable Solvatochromic Probes for Live-Cell Superresolution Imaging of Plasma Membrane Organization. Angew. Chem. Int. Ed. Engl. 2019, 58, 14920-14924.

(40) Niko, Y.; Didier, P.; Mely, Y.; Konishi, G.; Klymchenko, A. S. Bright and photostable push-pull pyrene dye visualizes lipid order variation between plasma and intracellular membranes. Sci. Rep. 2016, 6.

(41) Valanciunaite, J.; Kempf, E.; Seki, H.; Danylchuk, D. I.; Peyriéras, N.; Niko, Y.; Klymchenko, A. S. Polarity Mapping of Cells and Embryos by Improved Fluorescent Solvatochromic Pyrene Probe. Anal. Chem. 2020, 92, 6512-6520.

(42) Mazeres, S.; Joly, E.; Lopez, A.; Tardin, C.

Characterization of M-laurdan, a versatile probe to explore order in lipid membranes. F1000Res 2014, 3, 172.

(43) Collot, M.; Ashokkumar, P.; Anton, H.; Boutant, E.;

Faklaris, O.; Galli, T.; Mély, Y.; Danglot, L.; Klymchenko, A. S. MemBright: A Family of Fluorescent Membrane Probes for Advanced Cellular Imaging and Neuroscience. Cell Chem. Biol. 2019, DOI: 10.1016/j.chembiol.2019.01.009.

(44) Brouwer, A. M. Standards for photoluminescence quantum yield measurements in solution (IUPAC Technical Report). Pure Appl. Chem. 2011, 83, 2213-2228.

(45) Sakai, K.; Kaji, M.; Takamatsu, Y.; Tsuchiya, K.; Torigoe, K.; Tsubone, K.; Yoshimura, T.; Esumi, K.; Sakai, H.; Abe, M. Fluorocarbon-hydrocarbon gemini surfactant mixtures in aqueous solution. Colloids Surf. A Physicochem. Eng. Asp. 2009, 333, 26-31.

(46) Sezgin, E.; Kaiser, H. J.; Baumgart, T.; Schwille, P.; Simons, K.; Levental, I. Elucidating membrane structure and protein behavior using giant plasma membrane vesicles. Nat. Protoc. 2012, 7, 1042-1051.

(47) Sezgin, E.; Waithe, D.; Bernardino de la Serna, J.; Eggeling, C. Spectral imaging to measure heterogeneity in membrane lipid packing. ChemPhysChem 2015, 16, 13871394.

(48) Sezgin, E.; Gutmann, T.; Buhl, T.; Dirkx, R.; Grzybek, M.; Coskun, U.; Solimena, M.; Simons, K.; Levental, I.; Schwille, P. Adaptive lipid packing and bioactivity in membrane domains. PLoS One 2015, 10, e0123930.

(49) Daly, B.; Ling, J.; de Silva, A. P. Current developments in fluorescent PET (photoinduced electron transfer) sensors and switches. Chem. Soc. Rev. 2015, 44, 4203-4211.

(50) Dalvi-Malhotra, J.; Chen, L. Enhanced conjugated polymer fluorescence quenching by dipyridinium-based quenchers in the presence of surfactant. J. Phys. Chem. B 2005, 109, 3873-3878.

(51) Sun, L.-c.; Yang, Y.-f.; He, J.-j.; Shen, T. Fluorescence quenching of viologen on xanthene dyes in dyads. Dyes Pigm. 1995, 28, 275-279.

(52) Liu, J.-X.; Zhou, Q.-F.; Xu, H.-J. Quenching of zinc phthalocyanine excited states by viologen surfactant assemblies-The influence of microenvironment. Chin. J. Chem. 2010, 11, 120-125.

(53) Pantazis, A.; Westerberg, K.; Althoff, T.; Abramson, J.; Olcese, R. Harnessing photoinduced electron transfer to optically determine protein sub-nanoscale atomic distances. Nat. Commun. 2018, 9, 4738. 
(54) Sezgin, E.; Levental, I.; Grzybek, M.; Schwarzmann, G.; Mueller, V.; Honigmann, A.; Belov, V. N.; Eggeling, C.;

Coskun, U.; Simons, K.; Schwille, P. Partitioning, diffusion, and ligand binding of raft lipid analogs in model and cellular plasma membranes. Biochim. Biophys. Acta 2012, 1818, 17771784.

(55) Kaiser, H. J.; Lingwood, D.; Levental, I.; Sampaio, J. L.; Kalvodova, L.; Rajendran, L.; Simons, K. Order of lipid phases in model and plasma membranes. Proc. Natl. Acad. Sci. US A 2009, 106, 16645-16650.
(56) Zidovetzki, R.; Levitan, I. Use of cyclodextrins to manipulate plasma membrane cholesterol content: Evidence, misconceptions and control strategies. Biochim. Biophys. Acta Biomembr. 2007, 1768, 1311-1324.

(57) Liu, S.-L.; Sheng, R.; Jung, J. H.; Wang, L.; Stec, E.; O'Connor, M. J.; Song, S.; Bikkavilli, R. K.; Winn, R. A.; Lee, D.; Baek, K.; Ueda, K.; Levitan, I.; Kim, K.-P.; Cho, W. Orthogonal lipid sensors identify transbilayer asymmetry of plasma membrane cholesterol. Nat. Chem. Biol. 2017, 13, 268274.

\section{For TOC only}

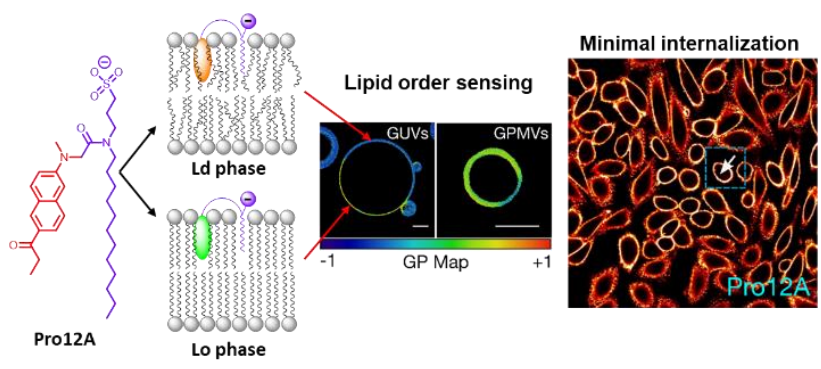

